\title{
Conquista e ocupação da Amazônia: a fronteira Norte do Brasil
}

\author{
REGINA MARIA A. FONSECA GADELHA
}

A HISTÓRIA da expansão territorial do Brasil ainda tem sido pouco pesquisada por nossa historiografia, apesar da importância estratégica e atual que reveste a questão. Entretanto, historiadores amazonenses, como Arthur Cézar Ferreira Reis, ex-governador do Amazonas, e Samuel Belchimor, contribuíram com relevantes obras para o conhecimento da história da ocupação e formação das fronteiras da região. Também a obra documental e os relevantes estudos legados pelo historiador português Jaime Cortesão estão a merecer renovada atenção da parte de historiadores e cientistas políticos brasileiros, se quisermos nos preparar melhor no necessário conhecimento da formação de nossas fronteiras.

Em decorrência, os equívocos com os quais se defronta o conhecimento da realidade amazônica decorrem da carência de ensinamentos geopolíticos mais sólidos, embasados em uma historiografia mais rigorosa acerca da legitimidade da ocupação portuguesa dos territórios amazônicos, que abrangeram no passado o estado do Maranhão e Grão-Pará. A maioria das contribuições existentes datam dos anos 1950-60 e hoje são pouco conhecidas. É o caso das obras fundamentais de Arthur César Ferreira Reis e de Jaime Cortesão. Por outro lado, os estudos recentes se prendem a questões como a denúncia dos latifúndios da região ou a necessária defesa ecológica da floresta e seus recursos, inclusive minerais, desconhecendo as origens da ocupação, da posse e dos direitos coloniais que nortearam as conquistas do Brasil português.

Desde 1974, ao iniciar as primeiras investigações acerca das missões jesuítas, eu me convencera da importância dos fundamentos geográficos e contingenciamentos das condições do habitat sobre os povos, consolidada pela leitura das obras de Jaime Cortesão, em especial Raposo Tavares e a formação territorial do Brasil (1966). A obra se inicia com um fundamental capítulo acerca da geografia e etnografia da América do Sul, em que o autor desenvolve a tese de que a posição e o espaço em que hoje se assenta o Estado brasileiro se explicam um pelo outro. Ou seja, posição e espaço facilitaram a ocupação territorial do país e, dessa forma, beneficiaram a ocupação da hinterlândia brasileira pelos portugueses, ainda no século XVI, posse que já estaria consolidada no século XVIII. Escreve Cortesão: 
Um dos mais extraordinários conjuntos hidrográficos do planeta, moldado sobre o relevo do continente e abrangendo a mais vasta unidade vegetal das Américas, envolve a área da floresta tropical num imenso arco e sistema de circulação fluvial. [...] Essa coordenação lógica, de tão grande importância na formação geográfica e orgânica do Brasil, avulta logicamente, quando sobrepomos ao mapa orográfico geral da América do Sul e o das suas grandes formações vegetais (Cortesão, 1966: 19).

O relevo e a hidrografia existentes do lado do território brasileiro contrastam com a verdadeira fronteira representada pelos contrafortes da cordilheira andina, que corta os domínios meridionais da América espanhola. Cortesão lembra a importância repressora dessa muralha, que foi um dos grandes obstáculos à penetração dos espanhóis na Amazônia. Sem falar na descoberta fundamental da prata de Potosi, que influenciou as decisões políticas imperiais dos monarcas espanhóis, levando-os a impedir qualquer abertura de caminho que pudesse interferir no rígido controle do contrabando e seus possíveis desvios, exercido pela Coroa sobre os caminhos que conduziam a prata americana para a Espanha (Gadelha, 1980: 135-49).

Em contraposição, porém, as medidas políticas adotadas contrariavam a realidade geográfica, pois para o leste, e em toda a extensão norte-sul, o relevo e a hidrografia do continente beneficiavam a expansão portuguesa. De fato, ao norte e ao sul se estendem as cabeceiras e os afluentes das duas maiores bacias fluviais quiçá do planeta, a amazônica e a platina, que correm relativamente paralelas em direção ao Atlântico e em direção contrária ao Pacífico. Essas bacias teriam sido responsáveis pela relativa facilidade com que se deu o deslocamento e integração dos homens ao espaço, e deste ao estado português. É sabido, afirma Cortesão, que antes mesmo da chegada dos europeus, os índios e, depois, os bandeirantes e sertanistas, mamelucos e portugueses que partiam de vários pontos do território vararam por terra e canoas de um rio a outro, na região comum das respectivas vertentes dos afluentes formadores dos rios Amazonas e Prata.

Sobre esse espaço continental, situado nos trópicos úmidos e rodeado insularmente pelo sistema hidrográfico platino-amazônico, de traços muito vigorosos, destacavam-se, envolvendo-o num arco de círculo irregular, certas zonas de relevo áspero, declive abrupto ou profunda depressão, que opunham forte obstáculo à expansão humana e que chamaremos faixas ou centros formadores de fronteira (Cortesão, 1966: 21).

A unidade geográfica compreendia outra, ainda mais sólida: a unidade cultural da ocupação humana, composta por povos largamente diferenciados daqueles contidos pela cordilheira andina e representados pelas civilizações maiaincáica, que todavia nunca excederam as bordas da floresta tropical equatoriana, venezuelana e boliviana. Porém, do outro lado da cordilheira, adentrando os limites da floresta tropical, os grupos humanos eram outros, conforme demonstrado pelos trabalhos do antropólogo francês Alfred Métraux, ao analisar o ex- 
tenso movimento migratório dos povos pré-colombianos (aruak, karib, tupi, guarani, jê e outros), que dominavam e controlavam o território da América do Sul, desde o Orinoco até o Prata, ocupando não somente o interior das terras como ainda a vasta extensão do litoral atlântico português (Métraux, 1927).

Regulava o Tratado de Tordesilhas, desde 1494, a partilha entre Espanha e Portugal das terras divididas do Atlântico. Esse tratado foi a verdadeira base em que se fundamentaram os tratados de fronteiras do século XVIII, entre os quais Utrecht, Santo Ildefonso e Madri.

As negociações entre Portugal e Espanha, que culminaram em Tordesilhas, se haviam iniciado desde a chegada do almirante Cristóvão Colombo a Sevilha, de retorno de sua viagem de descobrimento das terras americanas. Com avanços e recuos, as negociações levaram cerca de um ano e meio, obtendo os embaixadores portugueses, em 7 de junho de 1494, a assinatura do tratado, após haverem recusado veementemente aceitar as bulas anteriores outorgadas por Alexandre VI, que favoreciam os reis católicos de Espanha. (Cortesão, 1956: I, 1-lxxii).

Em sua brilhante introdução ao primeiro volume de Pauliceae lusitana monumenta historica, Jaime Cortesão indica que, à época dessas negociações, dentre todos os povos da Europa somente os portugueses tinham condição de possuir idéia aproximada sobre a localização geográfica mais correta da Índia, objetivo de Cristóvão Colombo. Relata e documenta os artifícios diplomáticos desenvolvidos por D. João II, verdadeiro jogo de diplomacia e astúcia visando obter o que considerava ser um direito já adquirido por Portugal, pois embora os soberanos de Espanha estivessem protegidos pelo papa espanhol, ele e seus ministros se encontravam escudados em maior e certo conhecimento experimental da estrutura geral do globo terrestre. Conhecimentos que foram lentamente adquiridos pelos pilotos portugueses, através de mais de cinquenta anos de experiências náuticas anteriores a Colombo (Cortesão, 1956: vii-x) (1).

O tratado considera que as "Índias", descobertas por Colombo, se iniciavam na ilha Espanhola (Haiti). Restava saber por onde, de fato, passaria a linha de demarcação de Tordesilhas, vagamente indicada pelo meridiano que dividia "de pólo a pólo" o oceano entre as ilhas do arquipélago de Cabo Verde e os continentes, ou seja, saber a partir de qual ilha do arquipélago se devia medir o meridiano e se a linha de demarcação devia ser contada sobre o paralelo dessa ilha ou sobre o paralelo do Equador. A lógica, assinala Cortesão, mandava que a medição fosse feita desde a ponta ocidental da ilha mais ocidental do arquipélago, isto é, a ilha de Santo Antão, até a ponta mais oriental de Espanhola (Cortesão, 1956: 1xilxii). Daí a importância das medições efetuadas por Duarte Pacheco e por Cristóvão Colombo, tendo por base a longitude da ponta oriental de Espanhola, conforme indicamos na nota 1 .

No entanto, lembra Cortesão, o objetivo das políticas de Espanha e de Portugal na época era assegurarem-se do caminho para as Índias. Confiando nos informes transmitidos por seu conselheiro, Pero de Covilhã, interessava a D. João 
II assegurar-se das terras do Oriente e, muito particularmente, as do Extremo Oriente, as célebres ilhas Molucas ou "da Banda", que então eram consideradas "verdadeira e mais rica mina de especiarias". Como não consta do texto do tratado nenhuma linha sobre estender o meridiano ao outro hemisfério do globo, é de supor que em 1492 a preocupação maior em efetuar a demarcação do Atlântico cabia a Espanha e não a Portugal. Somente alguns anos depois, quando os portugueses alcançaram as Molucas, é que Carlos V compreendeu o erro (2), pois D. João II não só reservara para Portugal a posse da verdadeira rota para as Índias, como uma grande parte do Brasil atual. Ao celebrar-se Tordesilhas, tanto os reis de Espanha como o de Portugal haviam se dado por satisfeitos. Os primeiros, na conviç̧ão de que eram os senhores da rota da Índia e o segundo porque estava certo de poder completar muito em breve o seu descobrimento (Cortesão, 1956: lxvii).

Porém, em relação às terras brasileiras, Cortesão afirma que o tratado já nasceu caduco. Desenvolve a tese de que, embora a extensão das terras pertencentes a Portugal se alargasse do delta amazônico até a ilha de Santa Catarina, a realidade geográfica do território ainda desconhecido pelos legisladores se imporia - sendo suficiente a visão geotopográfica da América do Sul para demonstrar que as fronteiras, obtidas pela diplomacia da época, não ofereciam base estável à formação de nenhum verdadeiro Estado.

Assim delimitado, esse território ficava ilaqueado e comprimido pelas duas bacias do Tocantins e do Paraná, excelentes vias de acesso e assédio, em mãos de inimigos, para o invadir e conquistar. Ao sul, a estreita faixa de terra desde o Rio de Janeiro até o litoral do atual estado de Santa Catarina, mais que nenhuma outra, seria inviável, como parte de um estado independente. Por outro lado, o meridiano de Tordesilhas amputava com violência a vasta unidade geográfica e econômica, rodeada como uma ilha pelas bacias fluviais de Paraguai e do Madeira. O mesmo se pode afirmar acerca da humanidade indígena (os tupi-guarani e os aruaque) que a habitava e oferecia tão notável contraste cultural com os quixua e aimara dos planaltos andinos. Ou os espanhóis, baixando o Amazonas e seus afluentes, de um lado, e, do outro, subindo o Paraná, restabeleciam aquela unidade, expulsando os portugueses da sua legítima mas inviável faixa ocidental; ou os segundos, aliados aos antigos possuidores da terra e seguindo o caminho oposto, realizavam a unidade da grande ilha Brasil, amazônica-platina (Cortesão, 1956: $\operatorname{lxx}-1 \mathrm{xxi})(3)$.

Isso explica porque, sob o pretexto das dificuldades de calcular a longitude exata do meridiano, os mapas cartográficos (tanto de portugueses como de espanhóis) dos séculos XVI e XVII tenham buscado falsear a representação do Brasil ou a das terras do Extremo Oriente. O certo é que nos últimos anos do século $\mathrm{XV}$, naus espanholas (Vicente Pinzon) e portuguesas (Duarte Pacheco) cruzaram a linha do Equador e estiveram em mares do Brasil, percorrendo desde o cabo de Santo Agostinho até a costa norte, na embocadura do rio Pará ou Ama- 
zonas. Após o descobrimento de Cabral, época melhor documentada, assinala-se da parte lusitana as expedições de João Coelho (1502 ou 1503); João de Lisboa e Diogo Ribeiro; e Fernão Froes, Francisco e Pero Corso, que partiram das costas de Pernambuco e atingiram o ponto mais extremo do cabo Norte (Amapá) (Reis: I, 32). Southey assinala ainda a presença de Luiz de Melo da Silva na região, por volta de 1555, cujos navios, ao saírem de Pernambuco, foram impelidos para o norte, tendo esse navegador atingido a ilha de Santa Margarida, lá encontrando os destroços da fracassada colonização iniciada em nome do rei de Espanha pelo primeiro adelantado do Amazonas, Francisco de Orellana (1551-1555) (Southey: I, 122).

O certo é que, ao menos desde 1513, naus portuguesas chegavam e ultrapassavam as costas da Guiana, como demonstrado pela documentação de Rio Branco, pesquisada por Ferreira Reis. Da mesma maneira, espanhóis a caminho da embocadura do grande rio já freqüentavam a nossa costa, o que é comprovado pelas passagens do Diário do descobrimento da costa do Brasil, de Pero Lopes de Souza (1530-32), em que esse capitão relata seu encontro com naus de Espanha que se dirigiam à foz do rio Marañon (28 de dezembro de 1530), obrigando-o a intimar o capitão espanhol que "não fosse àquela região", pois "o dito rio pertencia ao rei de Portugal” (4). Segundo o Diário, ao chegar em Pernambuco, Pero Lopes ordenou o envio de duas caravelas, para que "fossem descobrir o rio de Maranhã " (Souza, Pero Lopes de. Loc.cit. p. 453).

Do lado da Espanha, além da sabida viagem realizada por Vicente Pinzon ao Amazonas (1499-1500), passando pelo cabo de Santo Agostinho (Pernambuco), conhecemos o relato da expedição feita por Francisco de Orellana (1540-42), realizada por ordem do governador Gonzalo Pizarro. Partindo da província dos omágua conhecida por Malchifaro ou Maquipáro, Orellana desceu o grande rio até a sua foz, em território português. Devemos o relato dessa expedição ao frei dominicanoGaspar de Carvajal, que foi o primeiro cronista a descrever a geografia, a orografia e a etnografia dos numerosos grupos indígenas que povoavam o vale do Amazonas em toda a sua extensão (5). Alguns anos depois, a expedição de Pedro de Urzua (1560-61) tentava refazer o caminho traçado por Orellana, descendo o grande rio. Porém, esse capitão foi morto por um dos seus tenentes, Lope de Aguirre, que não conseguiu completar a missão de atingir o canal principal do Amazonas. Na verdade, Aguirre se perdeu entre os vários braços de igarapés e canais dos rios da região, subindo em direção ao norte até desembocar nas proximidades da ilha da Trindade, no litoral venezuelano.

Da parte da documentação portuguesa, um dos primeiros documentos conhecidos sobre o vale amazônico é a Carta de Diogo Nuñes (1553?), dirigida ao rei de Portugal, D. João III (Cortesão, 1956: I, 5-8, docs. 58:258-63) (6). Afirma esse português haver em 1538 descido o Amazonas desde o Peru, acompanhando a expedição de um mercador espanhol. Pede autorização a D. João III para empreender nova expedição à região, com a finalidade de conquistar e colo- 
nizar aquelas terras de Espanha, em troca das mesmas concessões que recebiam os espanhóis do seu rei. Na Carta, Diogo Nuñes relata trechos da viagem, afirmando haver encontrado, na província de Maquipáro, uma tribo de índios denominados chachapoas, que fabricavam armas e braceletes de ouro. Refere-se à facilidade de se passar do Amazonas ao Prata, conforme informações que recolhera de tribos. Um dos caminhos, escreve, partia de São Vicente por terra, atravessando as cabeceiras dos rios do Brasil (7).

As informações de Diogo Nuñes foram comprovadas pelos sertanistas desde a segunda metade do século XVII, quando portugueses e mamelucos, soldados e missionários, partindo da capitania do Grão-Pará, desbravaram os afluentes do Amazonas e os sertões desses rios, ampliando o território até o Mato Grosso. Esses caminhos das monções, que partiam de Belém e do Maranhão, atingiam as nascentes das já conhecidas bacias do Paraná e do Paraguai - ou, passando pelo Madeira e pelo Tocantins-Araguaia, caminhando para o leste, ligavam a bacia do Amazonas ao São Francisco. Completava-se, assim, o contorno das futuras fronteiras, que seriam reconhecidas pelo Tratado de Madri de 1750 (Cortesão, 1965: I, 418-20) (8).

Capistrano de Abreu já ressaltara, em esquema, a importância das bandeiras que partiam dos vários pontos da costa do Brasil, conquistando o território da hinterlândia: primeiro as bandeiras dos paulistas, que trilhando desde o planalto vicentino o caminho conhecido do piabirú tupi, ligaram o Paraná ao Paraguai, ampliando progressivamente as suas viagens até o sul de Mato Grosso, de onde atingiam os limites do território espanhol dos moxo e chiquito (Bolívia), subindo até o rio Guaporé. Ou, desde a segunda metade do século XVII, penetravam o Madeira, o Tapajós e o Araguaia-Tocantins, estabelecendo ligações com o vale do Amazonas. Ou, ainda, penetravam pelos caminhos que ligam o Paraíba ao vale do São Francisco, subindo os sertões em direção ao Parnaíba e o Itapicuru, de onde penetravam até o Piauí e o Maranhão, caminhos que haviam sido conquistados e abertos pelos sertanistas baianos e pernambucanos. Capistrano se refere em seguida às bandeiras que da Bahia saíram para os sertões, realizando o reconhecimento e a conquista das terras do São Francisco ao Parnaíba, ou que subiam até o Maranhão pelo Itapicuru ou, ainda, que pelo São Francisco adentravam-se nos sertões em direção ao Tocantins. Bandeiras que, de Sêrro e Minas Novas (Minas Gerais), aventuravam-se na busca do "rio do ouro" (9). Finalmente, Capistrano se refere às bandeiras que, partindo de Pernambuco, desbravaram os caminhos do norte, conquistando a região entre o Capibaribe e a serra de Ibiapaba, traçando a menor distância entre o litoral e os chamados "sertões de fora", do Piauí e do Maranhão (Abreu: 338).

Da origem desses três movimentos (sertanistas paulistas, baianos e pernambucanos) se formou o amálgama daqueles mamelucos que desbravaram os sertões do Maranhão, as águas e as florestas do Grão-Pará, ou seja, a Amazônia. Partindo do Grão-Pará, esses sertanistas foram responsáveis pela penetração dos 
luso-brasileiros através do grande rio, no rumo leste-oeste, daí se espalhando em todas as direções. De Belém, trilhando para o norte e subindo o Javari, ocuparam o território que, de outra maneira, teria sido conquistado pelos franceses advindos da Guiana; seguindo para o oeste, expandiram as fronteiras até o Napo e conquistaram o Solimões. No encontro das águas deste com o Negro, adentraram o rio para o norte, até o vale do rio Branco, de onde mamelucos e missionários portugueses - primeiro os jesuítas e, depois, os carmelitas - estabeleciam as primeiras ligações até o Orinoco, sem que encontrassem oposição de povoadores ou de autoridades espanholas (Reis: II, 19-22). Única exceção, nesse período, a contrariar o avanço português em direção ao noroeste foram os reclamos dos jesuítas espanhóis encarregados das missões dos mayná, como já ocorrera com os jesuítas do sul (as missões de Guarani) e, depois, os dos jesuítas encarregados das missões de moxos e de chiquitos, em território boliviano.

Se os estudos de Capistrano lhe permitiram compreender o amplo significado dessas bandeiras, faltou dimensionar o enorme alcance de tais feitos. Por sua vez, porém, Gilberto Freyre chama atenção para a "plasticidade" do português, virtude que amalgamou a identidade dos colonizadores em terras brasileiras (podemos concluir o mesmo dos espanhóis, em outras partes da América).

Mestiços foram os bandeirantes e sertanistas que conquistaram o território brasileiro e constituíram a raiz das linhagens familiares do Brasil. Porque essa "conquista" foi sobretudo resultado da intensa mestiçagem que integrou os portugueses no Brasil, transformando-os em "mamelucos" e em mestiços. Refirome ao amplo sistema de parentesco indígena (o compadrio tupi, semelhante ao cuñadazgo guarani, por nós já analisado em outro trabalho) (10), que permitiu acolher os europeus, suavizando os primeiros contatos. Contato fundamental, que permitiu aproximar os portugueses de seus habitantes e a conhecerem a terra, aprendendo a sobreviver em território hostil, que lhes ensinou os caminhos das matas, das serras e dos rios, e a dominar os segredos da natureza, dos animais e das plantas. Esses tupi, jê, aruak, cunhados e irmãos, aliados, servos e soldados foram uma força auxiliar que, armada com seus arcos e flechas, se mostrariam indispensável à conquista e à defesa do território, tornando possível a dominação e ocupação definitiva.

Os estudos de Arthur Cézar Ferreira Reis demonstram como a ocupação da fronteira norte e sua inflexão no rumo leste-oeste ligam-se definitivamente ao núcleo da colonização de Pernambuco. Assim como São Paulo de Piratininga foi o núcleo de irradiação da colonização para o sul e para Minas Gerais, a vila de Olinda foi o principal ponto de partida e de apoio à irradiação da penetração portuguesa no litoral setentrional até o Maranhão, se expandindo através da posse do Grão-Pará - expansão que adquiriu relevância, sobretudo entre 1580 e 1616, data da expulsão dos franceses e incorporação definitiva desses territórios à coroa de Portugal. 


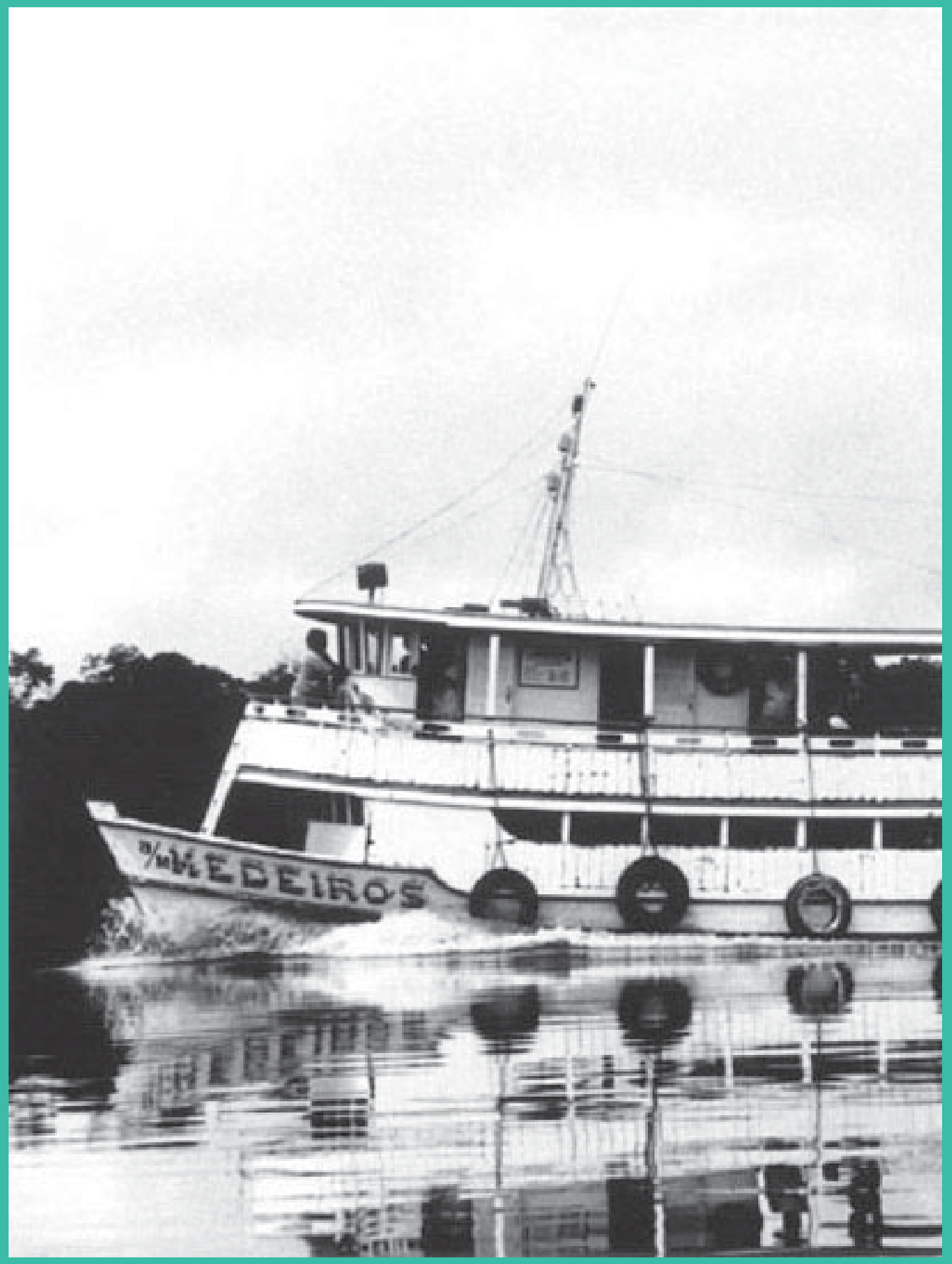




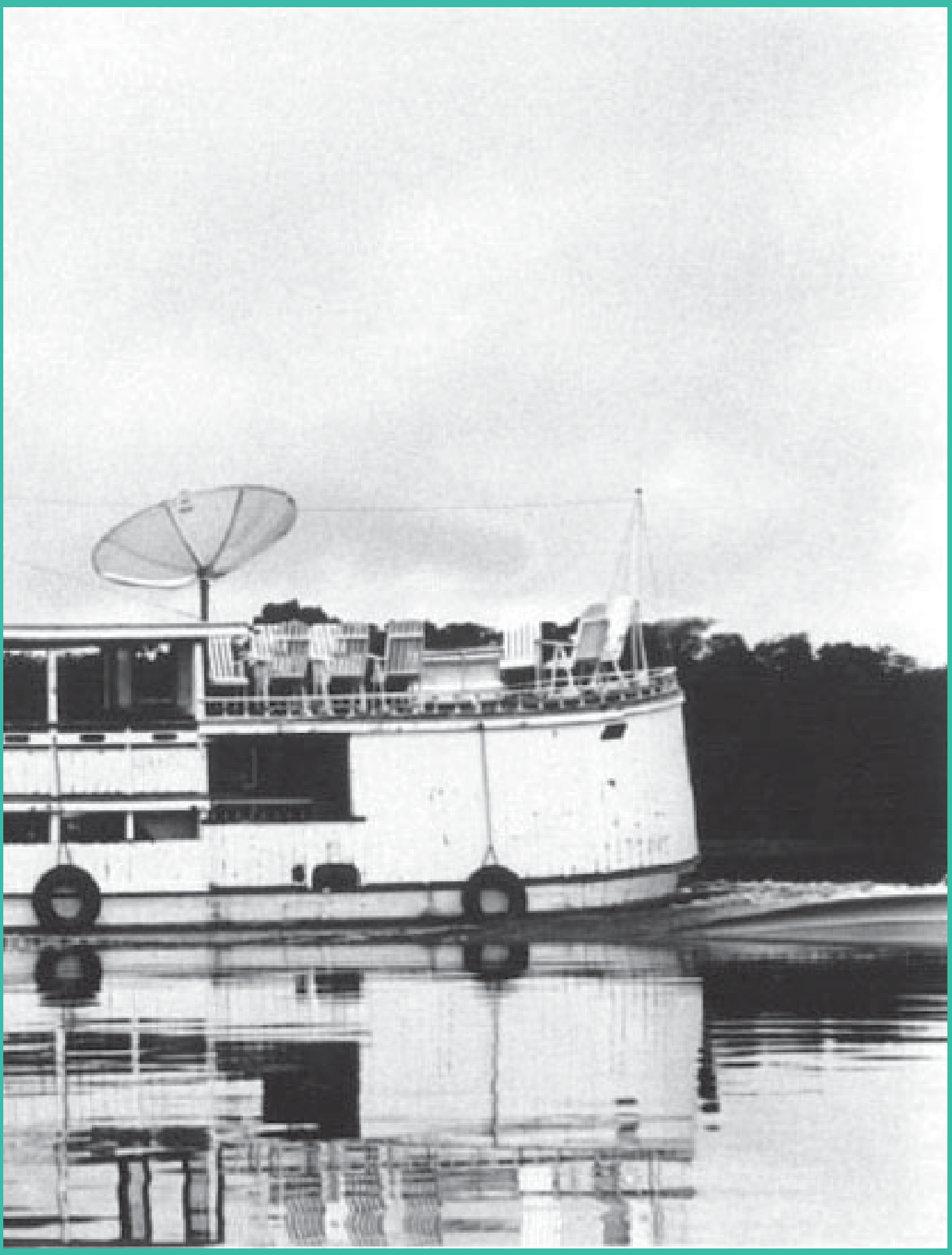

Barco fluvial, Rio Amazonas, Pará, 1995. Foto: Mignel Cbikaoka/Kamava-Kó. 
Desde muito, os franceses, conscientes das riquezas representadas pelo paubrasil e pelas especiarias dos sertões, desejavam assegurar-se de terras americanas pertencentes a Portugal. Conter suas investidas havia sido preocupação de D. João III e seus sucessores. Em 1574, pouco antes da união das coroas ibéricas, Frutuoso Barbosa, rico morador de Pernambuco, encarregou-se da missão de apaziguar os potiguara e tabajara da Paraíba, que mantinham relações com os franceses. Em 1580, somente, se obteve sucesso, graças ao auxílio prestado por Diego Flores Valdez, capitão espanhol que se dirigia ao rio da Prata, aportando em Pernambuco. Provados por essas jornadas, na década seguinte Manuel Mascarenhas Homem e Jerônimo de Albuquerque, filho mestiço do grande Jerônimo de Albuquerque e "língua" influente, completavam a conquista do litoral norte, elevando em 1598 o forte dos Três Reis Magos, futuro núcleo de Natal, na entrada do rio Potengi.

Em 1603, Pero Coelho de Sousa, em busca de resgate índio, penetrava o vale do Jaguaribe e os sertões da serra de Ibiapaba, jurisdição da capitania de Pernambuco, dominada pelos caeté. Porém, somente em 1608 Martim Soares Moreno, sobrevivente da malograda expedição de Pero Coelho, abriria a região onde, com auxílio do seu sogro, Jacuúna, principal dos caeté de Jaguaribe, elevara o forte de Nossa Senhora do Amparo. Esse forte foi por muito tempo o arraial e ponto mais avançado do interior em direção ao Maranhão, linha direta para os reforços de soldados e de sertanistas que, por terra, desde Pernambuco, estabeleciam os contatos com aquela capitania (Southey: II, 34-40).

Eram então os extremos da costa setentrional freqüentados por franceses e holandeses, que comerciavam com as tribos locais. Desde 1612, porém, os franceses fariam nova e mais perigosa investida de fixação no Brasil. Aliados aos tupinambá e liderados por Daniel de La Touche, senhor de La Ravardière, tentaram fixar uma colônia na ilha do Maranhão (São Luís). As notícias chegavam aos ouvidos de Madri e já em 1613 Felipe III ordenava ao novo governador do Brasil, Gaspar de Sousa, estabelecer residência em Olinda, de onde melhor poderia acompanhar e comandar as iniciativas destinadas a expulsar quaisquer invasores, especialmente os franceses, e prosseguir na descoberta e conquista daquelas "terras do rio das Amazonas" (Berredo, apud Southey: 54). Em 1614, Jerônimo de Albuquerque era nomeado pelo governador capitão-geral, encarregado da expulsão dos franceses, tendo Diogo Soares Moreno, parente de Martim Soares, como lugar-tenente. Breve chegaram os auxílios do forte de N. Sra. do Amparo, trazidos por Soares Moreno, Jacuúna e seus índios, enquanto do Rio Grande do Norte seu irmão, Felipe Camarão, subia com a sua gente. Auxiliado por eles, Martim Soares levantaria o forte de N. Sra. do Rosário, no litoral conhecido por Buraco das Tartarugas (Jericoacoara), Ceará, ponto mais próximo da ilha grande do Maranhão e da fortaleza dos franceses. Derrotados e rendidos finalmente em novembro de 1614, somente em 1615 La Ravardière entregaria o forte da ilha de São Luiz ao comandante Alexandre Moura, recém-chegado de Pernambuco com reforços militares. 
Se relatamos esses acontecimentos, é que eles são essenciais para a compreensão da ocupação da região norte, do vale e da hinterlândia amazônica, pois a expulsão dos franceses é o verdadeiro marco da conquista do litoral, no sentido leste-oeste, e do início da ocupação do Grão-Pará. Nesse sentido, algumas considerações merecem ser colocadas. Da parte de Madri, desviadas as atenções para o controle das riquezas de Potosi, que financiavam a política expansionista espanhola na Europa, os monarcas pouco se preocuparam com a defesa das extremidades dos seus territórios na América do Sul. Conforme indica Ab'Saber, o litoral amazônico, na posição equatorial e subequatorial, estende-se por aproximadamente 1.850 quilômetros, por setores do Amapá, Pará e Maranhão (11). De acordo com Tordesilhas, porém, os domínios herdados por Espanha de Portugal na extremidade norte, a partir do cabo Norte, reduziam-se a uma estreita nesga de terra até o delta do Amazonas. Felizmente, o mesmo não pensavam as autoridades de Portugal e os povoadores do Brasil, e dessa ação resultariam os esforços que conduziram à bem-sucedida campanha contra os franceses e, depois, à ocupação do Grão-Pará.

Gaspar de Sousa, por ordem do vice-rei de Portugal, ao nomear Alexandre Moura comandante da conquista, concedia a seu regimento poderes para que "se fizesse a jornada do gram Pará e Rio das amazonas, e se botassem delles os estrangeiros que aly residen" (Reis: I, 24). Em cumprimento a essas ordens, em 13 de dezembro de 1615 Moura nomeava Jerônimo de Albuquerque capitão-mor do Maranhão, com a responsabilidade de concretizar a colonização portuguesa na região, e Francisco Caldeira de Castelo Branco capitão-mor do Grão-Pará, dotado de regimento especial de Gaspar de Sousa, que lhe concedia autoridade suficiente para descobrir, conquistar e colonizar do Amazonas até o cabo Norte. Sobre esses episódios, considera Ferreira Reis:

A conquista da costa leste-oeste estava quase encerrada. Seu capítulo final, porém, ia ser escrito mais adiante, no vale amazônico, onde outros estrangeiros começavam a instalar-se e até onde chegara a bisbilhotice geográfica de La Ravardière e sua gente. A conquista da costa leste-oeste processava-se evidentemente dentro do meridiano tordesilhano, segundo o ponto de vista português (Reis: I, 23).

Em 25 de dezembro de 1615, Castelo Branco saía do forte de São Luiz, agora forte de São Filipe, em direção ao delta do Amazonas e, em janeiro de 1616, entrava no largo estuário do delta amazônico. Evitando ao norte a famosa Boca do Dragão, formada pela confluência das águas dos rios Pará e Tocantins, dirigiram-se ao sul, adentrando a baía de Guajará, formada pela foz dos rios Guamá, Maju e Acará, e iniciando na terra firme do território tupinambá a construção da paliçada da Casa Forte de Presépio (futura cidade de N. Sra. de Belém). Entre outros importantes sertanistas que se destacaram na conquista da região, acompanhava Castelo Branco o piloto Antônio Vicente Cochado, a quem se deve o mapeamento da costa do Maranhão ao Grão-Pará, e um jovem alferes que 
iria se destacar na conquista do vale do Amazonas, Pedro Teixeira (12). Além do perigo do enfrentamento com os tupinambá, que logo reagiram à presença dos luso-brasileiros, Castelo Branco teve de enfrentar o perigo holandês e inglês, que progressivamente instalava colônias e feitorias, penetrando desde a Guiana pelos rios amazônicos. Parece-nos, entretanto, que Ferreira Reis soube captar a preocupação crucial da época: Onde começava e terminava o extenso reino das águas?

Três fatores importam na compreensão da expansão das fronteiras portuguesas pela vastidão amazônica, que determinou a entrada definitiva dos mamelucos do Brasil e levou os lusitanos a ultrapassar os limites estabelecidos por Tordesilhas, incorporando definitivamente a Amazônia ao estado brasileiro. O primeiro fator, a que já nos referimos, é a realidade geográfica, expressa no mito da ilha Brasil e que diz respeito às raízes geográficas da expansão.

O segundo fator é, porém, menos conhecido dos historiadores brasileiros. Trata-se do regime dos ventos e das correntes marítimas, essenciais para a compreensão das possibilidades das navegações na época. Eles são explicativos também para o maior desenvolvimento comercial das capitanias do nordeste meridional, sobretudo Pernambuco, pois graças aos ventos era possível realizar a viagem entre Lisboa e Olinda-Recife em apenas quatro meses, dependendo da época do ano. Porém, poucos são os estudos que consideraram a importância desse fenômeno na reorganização administrativa do Brasil colonial e que provocou, desde 1621, a separação das capitanias do Maranhão e do Grão-Pará do Estado do Brasil (13).

De fato, o regime eólico explica a maior independência de que, desde o início da ocupação, gozaram as autoridades coloniais do Maranhão e do GrãoPará em relação ao governador-geral do Brasil, pela facilidade de comunicação direta mais rápida com Lisboa do que com Salvador. No entanto, pilotos e navegadores que cruzavam a linha do Equador, viajando pelo Atlântico com destino às capitanias do norte do Brasil ou para as Antilhas, sabiam que o bom êxito da travessia dependia fundamentalmente das correntes desses ventos. Ultrapassada a linha do Equador, os alísios sopram na direção leste-oeste e do mar para a terra, facilitando ou impedindo a travessia das naus. Uma observação mais atenta da carta do litoral setentrional brasileiro indica uma maior inflexão do litoral a partir de Jericoacoara (Ceará), recusando-se os ventos a facilitar a ultrapassagem e virada das naus com destino às capitanias de abaixo. Esse fenômeno, responsável pela mudança climática indicada por Ab'Saber em seu estudo do litoral maranhense (14), desde cedo foi conhecido dos pilotos portugueses, que temiam a inflexão para o Rio Grande do Norte, conduzindo as naus com maior rapidez da baía do Maranhão para Lisboa do que para Olinda e Recife ou Salvador. Constatara o perigo Martim Soares Moreno, quando ao tentar regressar do Maranhão, para onde se dirigira em missão de espionagem ao forte dos franceses, por ordem de Jerônimo de Albuquerque, seu navio não pôde regressar para o forte de Jericoacoara, tendo sido inúteis todos os esforços dos pilotos para dominar as monções dos alísios. Southey, relatando o fato, informa: 
Tinha este descoberta a colônia [dos franceses], e reconhecida bem a sua força, procurado voltar contra a moção. Coisa é esta quase impossível; tão constantes sopram os ventos em sentido oposto, que uma brisa do Maranhão para Pernambuco se olha para assim dizer como milagrosa. Perdido na tentativa um mastro, teve afinal de demandar a Espanha, como o caminho mais curto para casa; dali despachou desde logo o piloto, com a notícia para o Brasil, e foi êle mesmo expor o caso ao ministro em Madri (Southey: I, 56).

Anos depois, o padre Vieira comprovaria o fenômeno, quando o navio em que regressava para Pernambuco foi obrigado a se deter no Ceará e ele, impossibilitado de seguir viagem, teve de regressar a São Luiz.

Por seu lado, o caminho pelo interior das terras demonstrava também ser perigoso, devido à presença belicosa de grupos indígenas, que por muitos anos ainda resistiram aos portugueses, talvez em decorrência dos incertos períodos de estiagem, que tornavam penosas as travessias das terras mais secas do Piauí, Ceará e Pernambuco. Daí o motivo da maior independência de que gozaram, desde o início, os capitães-gerais e governadores do Maranhão e do Grão-Pará, cujos regimentos lhes davam amplos poderes, inclusive militar.

Porém, no caso da Amazônia, os alísios foram aliados dos sertanistas, que graças às monções podiam subir com facilidade os rios da região (os ventos) e descer (as correntes), em especial o grande rio dos tupi (rio Pará), como logo constatariam os pilotos da expedição de Pedro Teixeira, que subiram o curso do rio em direção às terras do Peru. Nesse sentido, apesar de os espanhóis reivindicarem a primazia da viagem de descobrimento de Francisco de Orellana, ao longo do curso do rio das Amazonas, coube a Pedro Teixeira realizar a primeira viagem oficial de descobrimento que subiu e desceu o longo curso desse rio, do estuário quase às nascentes, nas duas direções, reconhecendo os deltas de todos os seus grandes afluentes, levantando assim a primeira carta mais correta do curso do grande rio.

O terceiro fator é de caráter político.

Após a malograda tentativa de colonização do vale da Amazônia, pelo adelantado Francisco de Orellana (1551-55), e das desventuras sofridas por Gonzalo Pizarro e seus comandados a partir da Província de Maquipáro, tanto Carlos V como Felipe II tentaram inutilmente despertar o interesse dos espanhóis para a ocupação desses territórios. Nesse ciclo se inserem as doações com as quais os monarcas tentaram atrair alguns destacados soldados da conquista do Peru. De acordo com o historiador argentino Enrique de Gandia, citado por Ferreira Reis, as doações foram as seguintes. No século XVI: Vicente Yañez Pinzon (1501), Diego de Ordaz (1530), Francisco de Orellana (1551), Jerônimo de Aguayo (1552), Diego de Vargas (1554), Juan Despes (1563), Hernandez de Serpa e Pedro Molaver da Silva (1568), Juan Ortiz de Zarate (1569) e Antônio de Berrio (1585); no século XVII: Hernando de Oruna y la Hoz (1601) e Pedro de Betranilla (1604). 
Nenhum desses conquistadores, entretanto, parece ter querido se aventurar a perder recursos e vida na difícil empreitada. Alegavam os enormes esforços que se faziam necessários, sobretudo diante da possibilidade de obterem riqueza mais fácil no Peru ou em Nova Granada, ainda mais após o descobrimento do verdadeiro Eldorado, representado pelo cerro de Potosi. Já nessa ocasião a cordilheira prendia os conquistadores, revelando ser ela, de fato, a verdadeira fronteira que separaria os territórios das duas coroas.

Portanto, no século XVI e na primeira metade do século XVII, a ocupação pelos espanhóis do vale do Amazonas não ultrapassou as regiões mais próximas da cidade de Quito, na antiga província de Maquipáro, próxima às regiões dos rios Napo e Javari - as chamadas províncias dos iquitos, omáguas e pebas. A partir, porém, da segunda metade do século XVII, o povoamento português já se assenhoreava de quase todo o vale amazônico, ocupando o caminho aberto por Pedro Teixeira, que em 1639 tomara posse da região para Portugal, em nome do rei de Espanha, balizando a linha de fronteiras entre as duas nações (15). Pouco depois da Revolução de 1640, porém, Felipe IV preferiu confirmar as doações feitas por ele aos portugueses e também as anteriores, feitas por seu pai, desde 1621 (16). Assim, antes do final do século, sertanistas, soldados e missionários portugueses percorriam livremente o vale do Amazonas e ocupavam as suas margens e as de seus afluentes mais próximos no grande delta, atingindo o rio Negro desde 1656. Em 1669, Francisco da Mota Falcão consolidava a ocupação do Negro, elevando o forte de S. José do Rio Negro (núcleo inicial da cidade de Manaus), junto à confluência das águas deste rio com o Solimões.

Nada detinha esses sertanistas. Nesse sentido, é revelador que desde o século XVII a coroa de Espanha já preferia relegar aos missionários franciscanos e, depois, aos jesuítas e aos seus índios missioneiros, a missão de guardiões das fronteiras (17) e a defesa dos territórios periféricos mais extremos, demonstrando desinteresse pelo destino do vale e suas regiões silvícolas. A verdade é que, se alguma resistência houve da parte de Espanha, coube aos jesuítas e seus neófitos o único empenho pela defesa dessas fronteiras, impedindo a maior penetração dos brasileiros tanto nas regiões sul e oeste (as missões de Guarani, Moxo e Chiquito) como na região norte (missões de Mayná). Expulsos os jesuítas no século XVIII, por ordem do mesmo governo de Espanha, progressivamente as autoridades espanholas foram abandonando as áreas amazônicas - o que pôde ser largamente constatado pelos engenheiros brasileiros que no século XIX demarcaram as fronteiras oeste do Brasil. E quando, afinal, em 1892, o governo boliviano patrocinou uma expedição de redescobrimento às regiões silvícolas dos rios Beni e Inambari, até Madre di Dios, liderada por José Manuel Pando, futuro presidente da Bolívia, constatou que a área já estava ocupada por seringueiros brasileiros e passou a alegar o desconhecimento da importância econômica de um território que, entretanto, fora ocupado por brasileiros e vendido ao Brasil desde 1867 (18). 
Porém, no início do século XVII, desviados os interesses dos espanhóis do vale do grande rio, os monarcas não hesitaram em entregar aos capitães portugueses a responsabilidade pela vigilância, ocupação e colonização daquela região. A verdade é que bucaneiros, mercadores e colonos franceses, holandeses, ingleses e irlandeses já disputavam o acesso àquelas áreas, aproveitando-se da imensa costa desprotegida do território espanhol e dos poucos recursos disponíveis às autoridades coloniais para a defesa dessas regiões periféricas. Portanto, apesar dos alertas recebidos de funcionários reais e de missionários que melhor conheciam a região, pareceu natural ao rei de Espanha entregar aos súditos portugueses a responsabilidade pela vigilância e o controle da vastidão das terras penetradas pelo grande rio das Amazonas e seus afluentes, cuja posse dos limites Pedro Teixeira fixara, em 1639, lavrando ata diante de testemunhas espanholas e portuguesas, conforme transcrição de Ferreira Reis:

Que tomava posse das ditas terras, e sitio em nome de El Rey Felippe IV nosso Senhor pela Corôa de Portugal, se havia quem a dita posse contradissesse ou tivesse embargo, que lhe pôr, que alli estava o Escrivão da dita jornada, e descobrimento, que lhes receberia; por quanto alli vinhão Religiosos da Companhia de Jesus por ordem da Real Audiencia de Quito; e porque he terra remota, e povoada de muitos Indios, não houve por elles, nem por outrem, quem lhe contradissesse a dita pose... (Reis: 52-3).

No século XVIII, o Tratado de Madri (1750) somente daria razão aos sertanistas, representando o grande passo para a consolidação, embora ainda não definitiva, dos limites territoriais do estado do Brasil.

\section{Notas}

1 Esses conhecimentos permitiram ao navegador e cosmógrafo português Duarte Pacheco, que foi um dos negociadores de Tordesilhas, calcular o valor do grau terrestre em 18 léguas, ou seja, em 106,56 km, com erro de apenas 4\% em relação ao valor atual conhecido de $111 \mathrm{~km}$. Porém, Cristóvão Colombo calculara esse valor em 56 milhas (pouco mais de 14 léguas), ou seja, em menos de $84 \mathrm{~km}$. Duarte Pacheco errou por 4,5 km, escreve Cortesão, mas Colombo por mais de $27 \mathrm{~km}$ (Cortesão, 1956: I, ix).

2 Segundo cálculos realizados nos anos 40 pelo matemático historiador Gago Coutinho, o meridiano de Tordesilhas, contado sobre o paralelo desde a ponta mais ocidental da ilha de Santo Antão e aceitando o valor corrente desse grau à época (17,5 léguas), passaria a $37^{\circ} 30^{\prime}$ de longitude oeste, cortando o Brasil pela baía de Maracanã, ao norte, e cerca de Iguape, ao sul. A demarcação das Molucas só se deu em 1529, pelo Tratado de Saragosa, firmado entre D. João III e Carlos V. Os textos dos Tratados de Tordesilhas e de Saragosa foram publicados em Cortesão, Pauliceae lusitana monumenta historica, v. 1.

3 Esta opinião é também defendida por Arthur Cézar Ferreira Reis.

4 Doc. 107 em Pauliceae lusitana, v. 1. partes 5-8, pp. 437-512, especialmente p. 443. 
Trata-se, sem dúvida, da expedição de Diego de Ordas, que recebera autorização do rei de Espanha para explorar o litoral norte até o Maranhão (Southey: I, 101-2).

5 Carvajal, 1941: 11-79. Em reconhecimento por esse serviço, Francisco de Orellana requereu e recebeu do rei de Castela o título de adelantado das terras do Amazonas, denominadas por ele "Nova Andaluzia" (1544), organizando a primeira tentativa de colonização.

6 Varnhagen foi o primeiro autor a publicar esse documento. Cópia do texto anotado por Carlos Drumond foi publicada na Revista de História, São Paulo: USP, jan./ mar., 1950, 1, 95-102). Cortesão, no entanto, indica discrepância entre o documento original, que publica, e o texto de Varnhagen, também anotado por Drumond.

7 Segundo Cortesão, apenas em 1618 novo documento indicaria maiores conhecimentos geográficos acerca do rio Amazonas. Trata-se do Memorial de Simão Estácio da Silva, dirigido ao rei de Espanha, intitulado Intentos da jornada ao Pará, do qual transcreve alguns fragmentos em Raposo Tavares e a formação territorial do Brasil: "Este rio Pará, a que chamamos das Amazonas, tem dois nascimentos, um do rio Orellana ... nasce em Quito e serras do novo reino de Granada; outro, que chamam do Maranhão ... nasce um pouco ao norte do Serro de Potosi, nas serras do Peru ... e correndo mais de 700 léguas ao nordeste ... se ajunta com o de Orellana, mais de 400 léguas antes de entrar no mar" (1966: 1, 37-8).

8 Cópia do texto do Tratado de Madri acompanhado por outros documentos que se referem às fronteiras de Mato Grosso e da Amazônia em Reis, 1993: II, 116-29, em especial os artigos $3^{\circ}$ e $6^{\circ}-10^{\circ}$. Ainda, na mesma obra, "Tratado das Instrucções dos Comissários da Parte Norte. 24/06/1752", pp. 170-80.

9 A busca do "rio do Ouro" surge após o retorno da viagem de Pedro Teixeira (163639) desde a governação de Quito (vice-reino do Peru), divulgado pela publicação do Novo descobrimento do grande rio do Amazonas..., do jesuíta Cristóvão de Acuña, em que este indica haver a expedição encontrado, pouco abaixo do rio Yurua (Japurá), aldeias de índios que portavam "pequenos brincos de ouro". (Figueroa, Acuña et alii. 1986. pp. 76-7). Na imaginação popular, a busca do rio de ouro unira-se à lenda da existência do lago Dourado, procurado durante dois séculos pelos espanhóis. Comenta Ferreira Reis que se o rio Dourado não foi encontrado, a abundância do ouro de aluvião encontrado às margens dos afluentes do Amazonas serviu para compensar essas jornadas.

10 Gadelha, 1980: 74-8, 80-2.

11 Ab'Saber, 2001: 58. Veja também a importante descrição do litoral norte do Oiapoque a Belém, pp. 60-76.

12 As dificuldades enfrentadas por Castelo Branco para a sua missão, documentada pela correspondência entre este capitão, as autoridades do Maranhão e de Lisboa e Madri estão em Reis: 1, 24-31.

13 Extinto em 1652, o estado do Maranhão e do Grão-Pará foi restaurado em 1654. O Amazonas, no entanto, sempre possuiu um capitão-mor, com residência permanente em Belém e dotado de regimento especial, que lhe conferia independência de ação militar. Em 1760, Belém passava a ser sede do estado do Maranhão e do Grão-Pará (Reis: 1, 56).

14 Ab'Saber, 2001: 78-89. 
15 Ferreira Reis identifica o local no arraial de Franciscana, na confluência dos rios Napo e Aguarico, e transcreve trecho da ata do acontecimento (Reis: 1, 51-4). Cortesão também publicou documentos inéditos dessa expedição, em especial a importante "Relazion del gal. Pedro Tejera de el rio delas Amazonas para el ${ }^{\text {or }}$ Presidente. Ciudad de $S^{\text {an }}$ Fran $^{\text {co }}$. del Quito, 02/01/1639", onde esclarece a autorização oficial de sua viagem desde Belém (Cortesão, 1965: 1, 423-34).

16 As capitanias criadas ou doadas por ordem cronológica foram: capitania Real do GrãoPará (1621); capitania do Caeté (1627), a Feliciano Coelho de Carvalho, depois revogada em favor de Álvaro de Sousa (1634); capitania de Camutá (1637), a Feliciano Coelho de Carvalho; a importante e estratégica capitania do Norte (1637), a Bento Maciel Parente; capitania de Marajó (1655), a Antônio Sousa Macedo; capitania do Xingu (1681), a Gaspar de Sousa Freitas. A capitania de Gurupá não foi doada. Em todas estas capitanias, a coroa distribuiu sesmarias (Reis: 55).

17 Cf. Gadelha, 1994 e 1996.

18 Esse incidente originou a chamada "guerra do Acre" (1900-1903), conforme demonstra o estudo de Clara López Beltrán em Vangelista, 1996: 201-23.

Bibliografia

AB'SABER, Aziz Nacib. Litoral do Brasil (São Paulo: Metalivros, 2001).

ABREU, J. Capistrano de. Capitulos de história colonial (1500-1800) \& Os caminhos antigos e o povoamento do Brasil, $5^{\mathrm{a}}$ ed. (Brasília: UNB, 1963).

BELTRÁN, Clara Lopez. "Explorando el Oriente de Bolivia: Los Viajeros en el Siglo XIX" em Vangelista, Chiara. Fronteras, etnias, culturas. América Latina, siglos XVIXX (Quito, Equador: Abya-Yala, 1996), pp. 201-24.

CARVAJAL, Gaspar de. "Relação ... do novo descobrimento do famoso Rio Grande" em Descobrimentos do rio das Amazonas (São Paulo: Nacional, 1941).

CORTESÃO, Jaime. História do Brasil nos velhos mapas, 2 vols. (Rio de Janeiro: Instituto Rio Branco/Ministério das Relações Exteriores, 1965-1971).

Pauliceae lusitana monumenta historica, 3 vols. (Lisboa: Edição Comemorativa do IV Centenário da Fundação da Cidade de São Paulo, 1956), vv. 1-2. 1965).

. Raposo Tavares e a formação territorial do Brasil, 2 vols. (Lisboa: Portugália,

FIGUEROA, Francisco de; Acuña, Cristóbal de, et alii. Informes de jesuitas en el Amazonas. 1600-1684 (Iquitos, Peru: IIAP-CETA, 1996).

GADELHA, Regina Maria A. F. As missões jesuiticas do Itatim: estruturas sócio-econômicas do Paraguai colonial. Séculos XVI e XVII (Rio de Janeiro: Paz e Terra, 1980).

"Las Misiones Guaraní y el Problema de las Fronteras: 1610-1750" em Vangelista, Chiara. Fronteras, etnias, culturas. América Latina, siglos XVI-XX. (Quito, Equador: Abya-Yala, 1996), pp. 9-32.

"Los Guaraníes Misioneros en los Presidios de la Frontera Platense (16501768)", Anales de las V jornadas internacionales sobre las misiones jesuiticas (Montevidéu, Uruguai: Ministerio de Educación y Cultura, 1994), pp. 23-36. 
HOORNAERT, Eduardo (coord.) História da igreja na Amazônia (Petrópolis: Vozes, 1992).

MÉTRAUX, Alfred. "Migrations Historiques des Tupi-Guarani”, Journal de la Société des Américanistes de Paris, 19: pp. 1-45, (1927).

REIS, Arthur Cézar Ferreira. Limites e demarcações na Amazônia Brasileira, 2 vols. (Belém: Secretaria do Estado da Cultura, 1993). Volume 1: A fronteira colonial com a Guiana Francesa; Volume 2: A fronteira com as colônias espanholas.

SOUTHEY, Robert. História do Brasil, 3ª ed. (São Paulo: Obelisco, 1965), v. 1-3.

Regina Maria A. Fonseca Gadelha é historiadora, professora titular da Faculdade de Economia, Administração, Contabilidade e Atuárias da PUC-SP, e coordenadora do Curso de Especialização Economia Social e Desenvolvimento da América Latina, da FEA-PUCSP. 